\title{
Repeated counselling improves the antidiabetic effects of limited individualized lifestyle guidance in metabolic syndrome: J-STOP-METS final results
}

\author{
Masanori Munakata ${ }^{1}$, Hiroki Honma ${ }^{2}$, Mitugu Akasi ${ }^{3}$, Takaharu Araki ${ }^{4}$, Takahiko Kawamura ${ }^{5}$, \\ Masashi Kubota ${ }^{6}$, Tomoko Yokokawa ${ }^{7}$, Yoshihiro Numata ${ }^{8}$ and Toshihiro Toyonaga ${ }^{9}$, \\ on behalf of the J-STOP-MetS Study Group
}

The aim of this study was to examine whether additional repeated counselling further improves the health effects of limited, highly individualized lifestyle guidance in metabolic syndrome. One hundred and nine previously untreated metabolic syndrome patients received highly standardized and individualized lifestyle guidance for weight loss. A tentative goal of $5 \%$ weight reduction over the course of 2 months was set. Patients were then randomly assigned to either the multiple guidance group who received further counselling every 2 months $(n=52)$ or the single guidance group who received no further guidance until the final assessment 6 months later $(n=57)$. Baseline data between the multiple guidance and single guidance groups were similar. Body weight and waist circumference were significantly reduced, and liver function, lipid profiles and glucose metabolism were significantly improved in both groups. After adjustment for baseline data, the multiple guidance group showed considerably higher reduction in waist circumference and fasting blood sugar concentration than the single guidance group. These data suggest that additional counselling further improved the antidiabetic effects of limited individualized lifestyle guidance in metabolic syndrome.

Hypertension Research (2011) 34, 612-616; doi:10.1038/hr.2010.272; published online 13 January 2011

Keywords: J-STOP-MetS; lifestyle modification; metabolic syndrome; randomized controlled trial

\section{INTRODUCTION}

The high prevalence of metabolic syndrome is now a very serious health concern in many countries, including Japan. ${ }^{1}$ This national increase in the incidence of obesity is of great concern, because it will result in higher morbidity and mortality rates due to atherosclerotic cardiovascular diseases; consequently, an increase in health care costs is inevitable. A public preventive strategy is essential to reduce the morbidity of metabolic syndrome.

A recent Japanese governmental survey showed that $23 \%$ of men and $8.9 \%$ of women aged between 20 and 74 years have been diagnosed with metabolic syndrome (http://www.mhlw.go.jp/houdou/ 2006/05/h0508-1a.html). In 2008, the Japanese government started a new health care strategy that targeted early diagnosis of metabolic syndrome and intervention. In Japan, a single session of lifestyle guidance associated with an individual's annual health check-up has been routinely offered. However, this single guidance approach has not yielded good results, as indicated by the increasing incidence of obesity. The insufficient efficacy of the traditional single guidance approach may be due to its general and non-standardized manner.

In the new health care system, people diagnosed with metabolic syndrome first receive standardized and individualized lifestyle guidance, which may improve the efficacy compared with traditional guidance. Furthermore, they receive additional repeated counselling over a 6-month period. Previous studies confirmed that intensive, individualized lifestyle guidance reduces the risk of diabetes (DM) more than the general guidance in obese subjects. ${ }^{2-4}$ In most of those studies, however, guidance was qualitatively and quantitatively different between the intensive lifestyle guidance group and general guidance group. It remains unclear, therefore, if additional counselling further improves the efficacy of single individualized lifestyle guidance. To address this, in patients with metabolic syndrome, we compared the health effects between a group who received single individualized lifestyle guidance and a group who received additional repeated counselling. ${ }^{5}$

${ }^{1}$ Preventive Medical Center, Tohoku Rosai Hospital, Sendai, Japan; ${ }^{2}$ Preventive Medical Center, Hokkaido Central Rosai Hospital, Iwamizawa, Japan; ${ }^{2}$ Preventive Medical Center, Kantou Rosai Hospital, Kawasaki, Japan; ${ }^{4}$ Preventive Medical Center, Tokyo Rosai Hospital, Tokyo, Japan; ${ }^{5}$ Preventive Medical Center, Cyubu Rosai Hospital, Nagoya, Japan; ${ }^{6}$ Oosaka Rosai Hospital, Sakai, Japan; ${ }^{7}$ Preventive Medical Center, Kansai Rosai Hospital, Amagasaki, Japan; ${ }^{8}$ Preventive Medical Center, Chugoku Rosai Hospital, Kure, Japan and ${ }^{9}$ Preventive Medical Center, Kyusyu Rosai Hospital, Kokura, Japan

Correspondence: Dr M Munakata, Preventive Medical Center, Tohoku Rosai Hospital, 3-21 Dainohara 4, Aobaku, Sendai 981-8563, Japan.

E-mail: munakata.@tohokuh.rofuku.go.jp

Received 15 July 2010; revised 21 October 2010; accepted 29 November 2010; published online 13 January 2011 


\section{METHODS}

Subjects

We studied 109 previously untreated patients with the metabolic syndrome. We recruited patients who underwent annual health check-ups or those who were referred from outpatient clinics for further examination of hypertension, DM or dyslipidemia. The recruitment advertisement was announced in a health promotion lecture for the general population and in health-promoting magazines.

Diagnosis of metabolic syndrome in men is based on the new Japanese criteria that includes a waist circumference of $>85 \mathrm{~cm}$ with at least two of the following three cardiovascular risk factors: high blood pressure (systolic blood pressure $\geqslant 130 \mathrm{~mm} \mathrm{Hg}$ or diastolic blood pressure $\geqslant 85 \mathrm{~mm} \mathrm{Hg}$ ), hyperglycemia (fasting blood sugar $\geqslant 110 \mathrm{mg} \mathrm{dl}^{-1}$ ) or dyslipidemia (triglyceride $\geqslant 150 \mathrm{mg} \mathrm{dl}^{-1}$ or high-density lipoprotein $\left.<40 \mathrm{mg} \mathrm{dl}^{-1}\right) .{ }^{6}$ Although the female diagnostic cutoff value for waist circumference was set at $90 \mathrm{~cm}$ in the new Japanese criteria, we used $80 \mathrm{~cm}$ in this study because recent studies have shown that the most suitable cutoff level exists at around $80 \mathrm{~cm} .^{7,8}$ This is consistent with the Asian criteria. ${ }^{1}$ Exclusion criteria included: severe obesity (body mass index $\geqslant 35 \mathrm{~kg} \mathrm{~m}^{-2}$ ); uncontrolled DM (fasting blood glucose $\geqslant 160 \mathrm{mg} \mathrm{dl}^{-1}$ or HbAlc $\geqslant 8.0 \%$ ); renal failure (plasma creatinine concentration $\geqslant 1.5 \mathrm{mg} \mathrm{dl}^{-1}$ ); previous history of cardiovascular diseases, cancer or other serious diseases. This study was conducted in nine Preventive Medical Centers of the Rosai Hospital Groups.

The subjects visited each center after fasting overnight. Each subject was given a detailed questionnaire about their work, degree of physical activity in daily life, past and present illnesses, present medications, beverages, dietary, exercise habits, and stress at work and home. After anthropometric measurements, blood samples were collected from the antecubital vein for the determination of glucose and lipid profiles, uric acid concentration, and renal and liver functions. Blood pressure was measured with a standard mercury sphygmomanometer (MURANAKA, Osaka, Japan) with subjects in the sitting position after a rest of at least $5 \mathrm{~min}$. The mean of the two measurements was used for the analysis. Arterial stiffness was assessed by brachial-ankle pulse wave velocity (baPWV) with subjects in a supine position and was measured with an established device (Form PWV/ABI, Colin Corporation, Tokyo, Japan). Validity, reliability and clinical use of baPWV by this machine have been reported elsewhere. ${ }^{9,10}$

\section{Intervention program}

The main objective of this study was to examine if additional counselling further improves the efficacy of single lifestyle guidance with specific individual tailoring. So, all subjects received highly standardized and individualized lifestyle guidance for weight loss before randomization. First of all, a physician explained the pathophysiology of metabolic syndrome, the risk of future cardiovascular events due to this condition, the rationale for prescribing weight loss, and its importance in the maintenance of each subject's health. Obviously, each subject must be strongly motivated to participate in a weight reduction program in order to increase the chances of program success. As metabolic syndrome status is produced by chronic positive energy balance, subjects were requested to reduce calorie intake and increase physical activity. Methods of lifestyle modification were subsequently discussed with each specialist.

A trained nurse conducted the behavioral modification therapy. Behavioral therapy involved the following: (1) recognition of unhealthy dietary habits (late-night meals, eating between meals, excess alcohol consumption, absence of breakfast and so on) based on their questionnaire; (2) record keeping of body weight, waist circumference and physical activity; (3) stimulus control (that is, attention to antecedents of eating that promote excessive intake); (4) smoking cessation, if applicable. Each subject was requested to reduce $5 \%$ of his or her body weight over the first 2 months. The daily reduction in calorie intake and increase in physical activity required to achieve the set goal were discussed further with a dietician and an exercise trainer.

A dietician provided advice on how to achieve the reduction in calorie intake and modify dietary lifestyle. The cause of chronic increase in calorie intake varies among individuals. General attention was paid to (1) intake of three regular meals, (2) avoiding late-night food and eating between meals, (3) reducing lipid intake, (4) reducing salt intake, (5) increasing vegetable intake, (6) reducing alcohol intake and (7) ensuring sufficient intake of vitamins, minerals and other necessary nutrients based on the results of the questionnaire and face-to-face interview. Subjects who frequently take business trips received advice on how to choose a low calorie menu during business trips. Considering the above attentions, daily energy intake was rearranged so as to eliminate about $300-600 \mathrm{kcal}$ from the current status.

Finally, subjects were encouraged to increase physical activity to reduce fat volume. The exercise trainer examined each subject's physical condition and also conducted an ergometer test in several facilities to determine the safety level of daily exercise based on the cardiopulmonary responses to exercise. The goal of increased physical activity was at least $30 \mathrm{~min}$ of moderate physical activity a day at least 5 days a week. At the start of the study, the individual amount of physical activity was discussed with an exercise trainer and individual advice was given as to how to increase daily physical activity (walking, cycling, jogging, swimming and so on) and goals were set. Patients were advised to gradually increase their level of physical activity to avoid bone and joint damage. The total amount of increased physical activity per week corresponded to about 10 exercises, which is the recommended level of physical activity to ameliorate metabolic syndrome. ${ }^{11}$

\section{Randomization}

After the first guidance session, subjects were assigned to either the single guidance group or the multiple guidance group. Randomization was conducted according to the allocation sequence that was generated by the study-coordinating center and had been sent to each study center beforehand.

Subjects assigned to the multiple guidance group visited each center every 2 months and received a re-evaluation of body weight, waist circumference and body composition. If a subject's target body weight was not achieved at each visit, the cause was evaluated by an interview conducted by a trained nurse, dietician and exercise trainer, and corrected advice was presented to the subject. Subjects who successfully achieved target body weight were well appreciated and were encouraged to continue to make an effort to achieve next goal weight. Subjects who reached ideal body weight, that is, body mass index of $22 \mathrm{~kg} \mathrm{~m}^{-2}$ were requested to maintain the weight level.

Subjects assigned to the single guidance group were requested to practice the weight reduction program on their own at the same $5 \%$ loss rate every 2 months.

\section{Outcome measures}

Outcome measures were body weight, waist circumference and metabolic syndrome components, that is, blood pressures, lipid and glucose profiles. Arterial stiffness as assessed by the baPWV was also evaluated. These markers were studied in each subject at baseline and 6 months after the first guidance session. This study was approved by the ethics committees of all the Rosai Hospitals participating in this study. Written informed consent was obtained from all subjects.

\section{Statistical analysis}

Data were expressed as mean (s.d.). Differences between the groups at baseline were studied with an unpaired $t$-test, or Mann-Whitney test for continuous variables according to the distribution of the data. Plasma triglyceride concentration, aspartate aminotransferase, alanine aminotransferase and $\gamma$-glutamyl transpeptidase $(\gamma-G T)$ were studied by Mann-Whitney test and other variables were studied by $t$-test. Categorical variable was examined by $\chi^{2}$ analysis. The treatment effect was examined by paired $t$-test or Wilcoxon test. Comparison of the changes in each parameter between the single guidance and the multiple guidance groups was done by analysis of covariance. As higher baseline value tended to show greater reduction in response to intervention for each parameter, we adjusted the baseline value. All statistical analyses were performed with commercially available software (JMP version 5.0 for Windows, SAS Institute, Cary, NC, USA). A value of $P<0.05$ was considered statistically significant.

\section{RESULTS}

Seven subjects from each of the two groups dropped out of the study due to transfer of their work place. Finally, 50 subjects of the single guidance group and 45 of the multiple guidance group received posttreatment assessment after 6 months. 
Table 1 Baseline data of the single guidance and multiple guidance groups

\begin{tabular}{|c|c|c|c|}
\hline & $\begin{array}{l}\text { Single guidance } \\
\text { group }(\mathrm{n}=57)\end{array}$ & $\begin{array}{c}\text { Multiple guidance } \\
\text { group }(\mathrm{n}=52)\end{array}$ & $\mathrm{P}$ \\
\hline Age (years) & $50 \pm 10$ & $50 \pm 10$ & NS \\
\hline Men (\%) & $38(72)$ & $39(87)$ & NS \\
\hline Body weight (kg) & $75 \pm 11$ & $76 \pm 12$ & NS \\
\hline Waist (cm) & $92 \pm 8$ & $93 \pm 7$ & NS \\
\hline $\mathrm{BMI}\left(\mathrm{kg} \mathrm{m}^{-2}\right)$ & $26.8 \pm 3.7$ & $27.2 \pm 3.4$ & NS \\
\hline Systolic pressure (mm Hg) & $139 \pm 15$ & $139 \pm 12$ & NS \\
\hline Diastolic pressure $(\mathrm{mm} \mathrm{Hg})$ & $85 \pm 10$ & $85 \pm 9$ & NS \\
\hline $\mathrm{PWV}\left(\mathrm{cm} \mathrm{s}^{-1}\right)$ & $1502 \pm 263$ & $1474 \pm 215$ & NS \\
\hline AST $\left(|U|^{-1}\right)$ & $29 \pm 17$ & $31 \pm 13$ & NS \\
\hline $\operatorname{ALT}\left(|\cup|^{-1}\right)$ & $38 \pm 31$ & $45 \pm 28$ & NS \\
\hline$\gamma$-GT $\left(\mid U^{-1}\right)$ & $80 \pm 93$ & $80 \pm 55$ & NS \\
\hline Triglyceride $\left(\mathrm{mg} \mathrm{dl}{ }^{-1}\right)$ & $220 \pm 177$ & $175 \pm 81$ & NS \\
\hline $\mathrm{HDL}\left(\mathrm{mg} \mathrm{dl}^{-1}\right)$ & $52 \pm 13$ & $54 \pm 12$ & NS \\
\hline $\mathrm{LDL}\left(\mathrm{mg} \mathrm{dl}^{-1}\right)$ & $55 \pm 14$ & $55 \pm 13$ & NS \\
\hline FBS (mg dl ${ }^{-1}$ ) & $112 \pm 16$ & $112 \pm 19$ & NS \\
\hline $\mathrm{HbA} 1 \mathrm{c}(\%)$ & $5.5 \pm 0.6$ & $5.5 \pm 0.6$ & NS \\
\hline \multicolumn{4}{|c|}{$\begin{array}{l}\text { Abbreviations: } \gamma \text {-GT, } \gamma \text {-glutamyl transpeptidase; ALT, alanine aminotransferase; AST, aspartate } \\
\text { aminotransferase; BMI, body mass index; FBS, fasting blood sugar; HDL, high-density } \\
\text { lipoprotein; LDL, low-density lipoprotein; NS, non-significant; PWV, pulse wave velocity. } \\
\text { Data are mean values } \pm \text { s.d. } \\
\text { Statistical significance was determined by Mann-Whitney test for triglyceride, AST, ALT and } \\
\gamma \text {-GT, and by } t \text {-test for other continuous variables. Gender difference was examined by } \chi^{2} \\
\text { analysis. }\end{array}$} \\
\hline
\end{tabular}

Table 2 Effects of single guidance on clinical parameters

\begin{tabular}{|c|c|c|c|}
\hline & Before & 6 months after & $\mathrm{P}$ \\
\hline Body weight (kg) & $75 \pm 11$ & $73 \pm 10$ & $<0.0001$ \\
\hline Waist $(\mathrm{cm})$ & $92.8 \pm 8.4$ & $90.9 \pm 8.8$ & $<0.005$ \\
\hline $\mathrm{BMI}\left(\mathrm{kg} \mathrm{m}^{-2}\right)$ & $26.8 \pm 3.7$ & $25.9 \pm 3.7$ & $<0.0001$ \\
\hline Systolic pressure $(\mathrm{mm} \mathrm{Hg})$ & $139.7 \pm 15.5$ & $138.3 \pm 18.9$ & NS \\
\hline Diastolic pressure $(\mathrm{mm} \mathrm{Hg})$ & $85.5 \pm 9.7$ & $85.3 \pm 13.0$ & NS \\
\hline $\mathrm{PWV}\left(\mathrm{cm} \mathrm{s}^{-1}\right)$ & $1502 \pm 263$ & $1475 \pm 253$ & NS \\
\hline AST $\left(\mid U^{-1}\right)$ & $29.3 \pm 17.8$ & $24.8 \pm 11.3$ & $<0.05$ \\
\hline ALT $\left(\mid U^{-1}\right)$ & $37.8 \pm 31.0$ & $28.4 \pm 20.4$ & $<0.05$ \\
\hline$\gamma$-GT $\left(\left.I U\right|^{-1}\right)$ & $80.7 \pm 93.4$ & $58.7 \pm 54.9$ & $<0.05$ \\
\hline Triglyceride (mg dl ${ }^{-1}$ ) & $220.8 \pm 172.6$ & $172.6 \pm 95.1$ & $<0.01$ \\
\hline $\mathrm{HDL}\left(\mathrm{mg} \mathrm{dl} \mathrm{l}^{-1}\right)$ & $52.9 \pm 13.1$ & $55.3 \pm 14.1$ & $<0.05$ \\
\hline $\mathrm{LDL}\left(\mathrm{mg} \mathrm{dl}^{-1}\right)$ & $132.0 \pm 34.0$ & $136.2 \pm 34.7$ & NS \\
\hline FBS (mg dl-1) & $112.5 \pm 16.3$ & $110.0 \pm 24.8$ & NS \\
\hline HbAlc (\%) & $5.5 \pm 0.6$ & $5.4 \pm 0.6$ & $<0.005$ \\
\hline
\end{tabular}

Abbreviations: ALT, alanine aminotransferase; AST, aspartate aminotransferase; BMI, body mass index; FBS, fasting blood sugar; $\gamma$-GT, $\gamma$-glutamyl transpeptidase; HDL, high-density lipoprotein; LDL, low-density lipoprotein; NS, non-significant; PWV, pulse wave velocity.

Data are mean values \pm s.d.

Statistical significance was determined by Wilcoxon test for triglyceride, AST, ALT and $\gamma$-GT, and by paired $t$-test for other variables.

Table 1 shows the baseline data of the single guidance and the multiple guidance groups. Neither parameter differed between them. Table 2 demonstrates the effects of single guidance on body composition, blood pressure and biochemical variables. Body weight, waist circumference and body mass index were significantly reduced 6 months after single guidance as compared with baseline condition $(P<0.0001, P<0.005$ and $P<0.0001$, respectively). Single guidance significantly improved liver functions, as well as reduced triglyceride concentration $(P<0.01)$ and HbAlc $(P<0.005)$. High-density lipoprotein concentration increased as compared with baseline data $(P<0.05)$, but low-density lipoprotein $(\mathrm{LDL})$ concentration remained
Table 3 Effects of multiple guidance on clinical parameters

\begin{tabular}{|c|c|c|c|}
\hline & Before & 6 months after & $\mathrm{P}$ \\
\hline Body weight (kg) & $76.4 \pm 12.7$ & $72.3 \pm 12.1$ & $<0.0001$ \\
\hline Waist (cm) & $93.2 \pm 7.2$ & $88.4 \pm 8.3$ & $<0.0001$ \\
\hline BMI $\left(\mathrm{kg} \mathrm{m}^{-2}\right)$ & $27.2 \pm 3.4$ & $25.8 \pm 3.5$ & $<0.0001$ \\
\hline Systolic pressure $(\mathrm{mm} \mathrm{Hg})$ & $139.3 \pm 11.6$ & $134.4 \pm 18.1$ & $<0.05$ \\
\hline Diastolic pressure $(\mathrm{mm} \mathrm{Hg})$ & $85.3 \pm 9.5$ & $84.0 \pm 11.0$ & NS \\
\hline $\mathrm{PWV}\left(\mathrm{cm} \mathrm{s}^{-1}\right)$ & $1474 \pm 215$ & $1431 \pm 225$ & $<0.05$ \\
\hline AST $\left(\left.I U\right|^{-1}\right)$ & $31.2 \pm 13.4$ & $26.5 \pm 11.9$ & $<0.005$ \\
\hline $\operatorname{ALT}\left(I \cup I^{-1}\right)$ & $45.3 \pm 28.7$ & $31.7 \pm 20.2$ & $<0.0001$ \\
\hline$\gamma$-GT $\left(\left.I U\right|^{-1}\right)$ & $80.1 \pm 55.5$ & $54.2 \pm 37.1$ & $<0.0001$ \\
\hline Triglyceride $\left(\mathrm{mg} \mathrm{dl}^{-1}\right)$ & $175.9 \pm 81.6$ & $147.4 \pm 67.5$ & $<0.005$ \\
\hline $\mathrm{HDL}\left(\mathrm{mgdl}^{-1}\right)$ & $54.7 \pm 12.9$ & $55.8 \pm 13.3$ & NS \\
\hline LDL $\left(\mathrm{mg} \mathrm{dl}^{-1}\right)$ & $142.3 \pm 46.4$ & $137.7 \pm 51.5$ & NS \\
\hline FBS (mg/dl) & $111.6 \pm 19.8$ & $102.5 \pm 17.2$ & $<0.0001$ \\
\hline $\mathrm{HbAlc}(\%)$ & $5.5 \pm 0.6$ & $5.3 \pm 0.6$ & $<0.001$ \\
\hline
\end{tabular}

Abbreviations: ALT, alanine aminotransferase; AST, aspartate aminotransferase; BMI, body mass index; FBS, fasting blood sugar; $\gamma$-GT, $\gamma$-glutamyl transpeptidase; HDL, high-density lipoprotein; LDL, low-density lipoprotein; NS, non-significant; PWV, pulse wave velocity.

Data are mean values \pm s.d.

Statistical significance was determined by Wilcoxon test for triglyceride, AST, ALT and $\gamma$-GT, and by paired $t$-test for other variables.

Table 4 Comparison of the changes in each parameter between the single guidance and multiple guidance groups

\begin{tabular}{|c|c|c|c|}
\hline & $\begin{array}{c}\text { Single guidance } \\
\text { group }\end{array}$ & $\begin{array}{l}\text { Multiple guidance } \\
\text { group }\end{array}$ & $P$ \\
\hline Body weight (kg) & $-2.5 \pm 4.7$ & $-4.1 \pm 4.6$ & NS \\
\hline Waist $(\mathrm{cm})$ & $-1.9 \pm 5.7$ & $-4.8 \pm 5.6$ & 0.02 \\
\hline BMI $\left(\mathrm{kg} \mathrm{m}^{-2}\right)$ & $-0.8 \pm 1.6$ & $-1.41 \pm 1.6$ & NS \\
\hline Systolic pressure (mm Hg) & $-1.7 \pm 14.1$ & $-4.9 \pm 14.0$ & NS \\
\hline Diastolic pressure $(\mathrm{mm} \mathrm{Hg})$ & $-0.5 \pm 10.6$ & $-2.0 \pm 10.0$ & NS \\
\hline $\mathrm{PWV}\left(\mathrm{cm} \mathrm{s}^{-1}\right)$ & $-27 \pm 134$ & $-55 \pm 134$ & NS \\
\hline AST $\left(\left.I U\right|^{-1}\right)$ & $-4.9 \pm 9.1$ & $-4.2 \pm 8.7$ & NS \\
\hline $\operatorname{ALT}\left(\mid \mathrm{UI}^{-1}\right)$ & $-11.2 \pm 14.8$ & $-11.5 \pm 14.7$ & NS \\
\hline$\gamma$-GT $\left(\mid U^{-1}\right)$ & $-14.5 \pm 24.0$ & $-24.4 \pm 23.4$ & 0.03 \\
\hline Triglyceride $\left(\mathrm{mg} \mathrm{dl}^{-1}\right)$ & $-21 \pm 77$ & $-35 \pm 67$ & NS \\
\hline $\mathrm{HDL}\left(\mathrm{mgdl} \mathrm{l}^{-1}\right)$ & $2.4 \pm 7.7$ & $1.3 \pm 7.3$ & NS \\
\hline $\mathrm{LDL}\left(\mathrm{mg} \mathrm{dl}{ }^{-1}\right)$ & $5.1 \pm 26.1$ & $-4.0 \pm 25.4$ & NS \\
\hline $\mathrm{FBS}\left(\mathrm{mg} \mathrm{dl^{-1 }}\right)$ & $-2.5 \pm 14.1$ & $-9.0 \pm 14.0$ & 0.03 \\
\hline $\mathrm{HbA} 1 \mathrm{c}(\%)$ & $-0.12 \pm 0.35$ & $-0.23 \pm 0.38$ & NS \\
\hline
\end{tabular}

Abbreviations: ALT, alanine aminotransferase; AST, aspartate aminotransferase; BMI, body mass index; FBS, fasting blood sugar; $\gamma$-GT, $\gamma$-glutamyl transpeptidase; HDL, high-density lipoprotein; LDL, low-density lipoprotein; NS, non-significant; PWV, pulse wave velocity Data are mean values \pm s.d.

Statistical significance was determined by analysis of covariance adjusted for baseline value.

unchanged. Table 3 shows the effects of multiple guidance on body composition, blood pressure and biochemical variables. The trends observed in the multiple guidance group were similar to those of the single guidance group. Systolic blood pressure, baPWV and fasting blood sugar concentration were significantly lowered in the multiple guidance group $(P<0.05, P<0.05$ and $P<0.0001$, respectively). Table 4 compares the change in each parameter between the single guidance and the multiple guidance groups after adjustment of the baseline value. The reduction in waist circumference was greater in the multiple guidance group than in the single guidance group ( -4.8 (5.6) vs. $-1.9(5.7) \mathrm{cm}, P=0.02)$. The percent reduction in body weight 


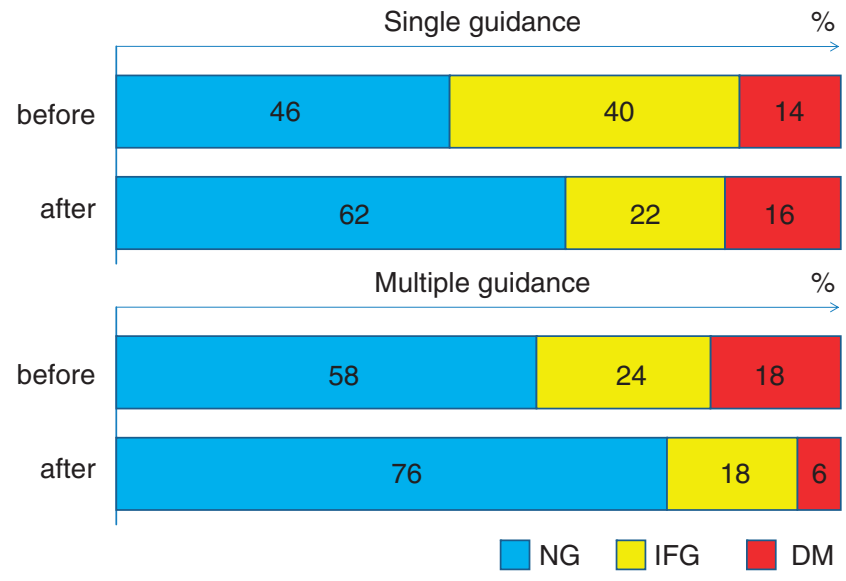

Figure 1 Percent changes in normoglycemia (NG), impaired fasting glucose (IFG) and diabetes (DM) before and after guidance in each group.

tended to be greater in the multiple guidance group than in the single guidance group, although this difference did not reach a statistically significant level $(-5.1$ vs. $-3.1 \%, P=0.08)$. In total, 17 out of 45 subjects completed multiple guidance $(37.7 \%)$ and 10 out of 50 subjects completed single guidance $(20 \%)$ achieved $>5 \%$ body weight reduction $(P=0.075)$.

The $\gamma$-GT $\left(-24.4\right.$ (23.4) vs. -14.5 (24.0) $\left.\mathrm{IUl}^{-1}, P=0.03\right)$ and fasting blood sugar concentration $(-9.0$ (14.0) vs. -2.5 (14.1) mg dl ${ }^{-1}, P=0.03$ ) were more greatly reduced in the multiple guidance group than in the single guidance group. Figure 1 shows the percentage of normoglycemia, impaired fasting glucose and DM before and after guidance in each group. The cutoff values for impaired fasting glucose and DM were 110 and $126 \mathrm{mg} \mathrm{dl}^{-1}$, respectively. The frequency of DM decreased from $8(18 \%)$ to $3(6 \%)$ in the multiple guidance group, while this frequency increased from 7 (14\%) to $8(16 \%)$ in the single guidance group. The frequency of impaired fasting glucose decreased from $20(40 \%)$ to $11(22 \%)$ in the single guidance group and $11(24 \%)$ to $8(18 \%)$ in the multiple guidance group, respectively. Changes in other parameters did not differ between the two groups.

\section{DISCUSSION}

The Japanese government started a new health care strategy in 2008 , in which patients with the metabolic syndrome are obligated to receive repeated lifestyle guidance after an annual health examination. In this new health care system, people diagnosed with metabolic syndrome are given repeated counselling in addition to basic individualized lifestyle guidance. However, it remains unclear whether such repeated counselling adds further merit to single session of individualized guidance. To address this issue, we compared the health effects between a group of patients with metabolic syndrome who received a single highly individualized lifestyle guidance and a group of patients with metabolic syndrome who was given further repeated counselling.

Both the single guidance and the multiple guidance approaches offered in this study significantly reduced body weight and waist circumference and lowered triglyceride concentration and HbAlc level. Liver functions also significantly improved in both groups. However, reductions in waist circumference, fasting blood glucose concentration and $\gamma$-GT were more markedly reduced in the multiple guidance group than in the single guidance group. These data showed that repeated guidance further improved the health effects of limited, highly individualized lifestyle guidance in patients with metabolic syndrome.

It has been well confirmed by large clinical trials such as the Finnish Diabetes Prevention Study or the Diabetes Prevention Program that individualized lifestyle modification reduces the risk of DM in obese patients. ${ }^{2,3}$ However, most of those studies compared one group who received highly individualized guidance and one group who received general guidance. The former group was in many cases more frequently guided than the latter. So, the guidance was qualitatively and quantitatively different between the intensive lifestyle guidance group and the control group. Our study showed for the first time that the efficacy of single tailored lifestyle guidance is further improved by repeated follow-up counselling. In fact, the frequency of DM reduced from 18 to $6 \%$ in the multiple guidance group, while the frequency of DM slightly increased in the single guidance group (14 vs. 16\%). Our data supports the Japanese government's strategy that legally requires metabolic syndrome patients to receive repeated lifestyle guidance.

Blood pressure remained unchanged although lipid and glucose metabolisms improved in the single guidance group. This means that the effect of weight loss on blood pressure appears to be less than on other components of metabolic syndrome. This is inconsistent with the previous report showing that even a small $(2-3 \mathrm{~kg})$ net weight reduction might be beneficial for the control of hypertension in obese subjects. ${ }^{12}$ Greater weight loss may further reduce blood pressure and vascular load, because systolic blood pressure and baPWV were significantly lowered in the multiple guidance group. The reduction in the PWV means a softening of the arterial tree, possibly leading to the prevention of arterial damage. The percentage of body weight reduction in the single guidance and multiple guidance groups was 3 and 5\%, respectively. Thus, we may need at least a $5 \%$ reduction in body weight for high blood pressure control as well as for improving arterial stiffness in metabolic syndrome. It has been reported that high blood pressure is a most common component of Japanese metabolic syndrome patients. ${ }^{13,14}$ Furthermore, Noda et al. ${ }^{15}$ have shown in the Japan public health center-based study that high blood pressure is a most strong risk factor for cardiovascular events among metabolic syndrome components. We therefore, should establish lifestyle guidance, which focuses more on blood pressure control of patients with metabolic syndrome.

Another new finding of our study is that repeated guidance significantly reduced $\gamma$-GT activity compared with single guidance. Although $\gamma$-GT activity has been considered to be an index of hepatobiliary dysfunction and alcohol abuse, recent epidemiological and pathological studies have suggested its independent role in the pathogenesis and clinical evolution of cardiovascular disease. ${ }^{16,17}$ The prospective study by Ruttmann ${ }^{18}$ of 163944 Austrian adults studied for 17 years shows that $\gamma$-GT is independently associated with cardiovascular mortality independent of all confounders, including liver function and alcohol use. This has been confirmed in both unselected populations and patients with ascertained coronary artery disease. ${ }^{19,20}$ The higher $\gamma$-GT activity seen in metabolic syndrome may be attributable to many factors including alcohol abuse, insulin resistance, liver steatosis and some genetic factors. ${ }^{17}$ We failed to clarify which mechanism was responsible for the greater reduction in $\gamma$-GT activity in the multiple guidance group, but these data surely suggest that multiple guidance provides another better health effect than single guidance in metabolic syndrome.

LDL concentration, a well-known coronary risk factor, remained unchanged not only in the single guidance group but also in the multiple guidance group. This means that LDL metabolism is 
minimally dependent on visceral fat accumulation. Our data are consistent with the previous report showing that LDL concentration remained unchanged even after significant body weight reduction in obese subjects. ${ }^{2}$ Thus, lifestyle guidance for reducing LDL is not similar to that used for decreasing abdominal fat accumulation.

There are several limitations in this study. First, we failed to gather the anticipated number of subjects. This may have lowered the power to discriminate the health effects between the multiple guidance and the single guidance groups. In other words, this study might underestimate the efficacy of multiple guidance compared with single guidance. In fact, post hoc analysis has shown that the number needed to create the difference of body weight between the multiple guidance and the single guidance groups was 143 for each arm, which is very similar to our predicted number of 180 including a $20-30 \%$ attrition rate. $^{5}$ Yet, we found that waist circumference and fasting blood sugar concentration were significantly lowered in the multiple guidance group than in the single guidance group. These results support the notion that waist circumference is a more sensitive marker for change in visceral fat and glucose metabolism than body weight in metabolic syndrome. ${ }^{21}$ Second, we did not evaluate the change in the quality of life, which is an important aspect for the maintenance of long-term behavioral changes. Third, the study period was only 6 months; thus, its long-term effects are unclear. Finally, we did not examine the cost effectiveness. To further confirm the rationality of repeated lifestyle guidance for metabolic syndrome, we must clarify if the cost for repeated lifestyle guidance is lower than the expected medical expenditure. The latter three are important issues that should be addressed in future.

In conclusion, our study showed that additional repeated counselling improved the antidiabetic effects of single individualized lifestyle guidance in metabolic syndrome. Our data supports the Japanese government's strategy that legally requires metabolic syndrome patients to receive repeated lifestyle guidance.

1 Alberti KG, Zimmet P, Shaw J, IDF Epidemiology Task Force Consensus Group. The metabolic syndrome-a new worldwide definition. Lancet 2005; 366: 1059-1062.

2 Tuomilehto J, Lindström J, Eriksson JG, Valle TT, Hämäläinen H, Ilanne-Parikka P, Keinänen-Kiukaanniemi S, Laakso M, Louheranta A, Rastas M, Salminen V, Uusitupa M, Finnish Diabetes Prevention Study Group. Prevention of type 2 diabetes mellitus by changes in lifestyle among subjects with impaired glucose tolerance. $N$ Eng/ J Med 2001; 344: 1343-1350.

3 Knowler WC, Barrett-Connor E, Fowler SE, Hamman RF, Lachin JM, Walker EA, Nathan DM, Diabetes Prevention Program Research Group. Reduction in the incidence of type 2 diabetes with lifestyle intervention or metformin. N Engl J Med 2002; 346: 393-403.
4 Mensink M, Feskens EJ, Saris WH, De Bruin TW, Blaak EE. Study on Lifestyle Intervention and Impaired Glucose Tolerance Maastricht (SLIM): preliminary results after one year. Int J Obes Relat Metab Disord 2003; 27: 377-384.

5 Munakata M, Honma H, Akasi M, Araki T, Kawamura T, Kubota M, Yokokawa T, Maruhashi A, Toyonaga T, J-STOP-MetS Study Group. Japanese study to organize proper lifestyle modifications for metabolic syndrome (J-STOP-MetS): design and method. Vasc Health Risk Manag 2008; 4: 415-420.

6 The Examination Committee of Criteria for 'Obesity Disease' in Japan; Japan Society for the Study of Obesity. New criteria for 'Obesity Disease' in Japan. Circ J 2002; 66: 987-992.

7 Hara K, Matsushita Y, Horikoshi M, Yoshiike N, Yokoyama T, Tanaka H, Kadowaki T. A proposal for the cutoff point of waist circumference for the diagnosis of metabolic syndrome in the Japanese population. Diabetes Care 2006; 29: 1123-1124.

8 Doi Y, Ninomiya T, Hata J, Yonemoto K, Arima H, Kubo M, Tanizaki Y, Iwase M, lida M, Kiyohara Y. Proposed criteria for metabolic syndrome in Japanese based on prospective evidence: the Hisayama study. Stroke 2009; 40: 1187-1194.

9 Munakata M, Ito N, Nunokawa T, Yoshinaga K. Utility of automated brachial ankle pulse wave velocity measurements in hypertensive patients. Am J Hypertens 2003; 16: 653-657.

10 Munakata M, Nunokawa T, Tayama J, Yoshinaga K, Toyota T. Brachial-ankle pulse wave velocity as a novel measure for arterial stiffness: present evidence and perspectives. Curr Hypertens Rev 2005; 1: 223-234.

11 Jakicic JM, Clark K, Coleman E, Donnelly JE, Foreyt J, Melanson E, Volek J, Volpe SL, American College of Sports Medicine position stand. Appropriate intervention strategies for weight loss and prevention of weight regain for adults. American College of Sports Medicine. Med Sci Sports Exerc 2001; 33: 2145-2156.

12 Davis BR, Blaufox MD, Oberman A, Wassertheil-Smoller S, Zimbaldi N, Cutler JA, Kirchner K, Langford HG. Reduction in long-term antihypertensive medication requirements. Effects of weight reduction by dietary intervention in overweight persons with mild hypertension. Arch Intern Med 1993; 153: 1773-1782.

13 Shimamoto K. How to spread the concept of metabolic syndrome. Nippon Rinsho 2006; 64(Suppl 9): 13-16. (Japanese).

14 Kawada T, Kuratomi Y, Kanai T, Suto S, Nishime A, Koizumi M, Nakano N. Anthropometric obesity indices and metabolic syndrome in Japanese working men. Work 2009; 34: 89-94.

15 Noda H, Iso H, Saito I, Konishi M, Inoue M, Tsugane S, JPHC Study Group. The impact of the metabolic syndrome and its components on the incidence of ischemic heart disease and stroke: the Japan public health center-based study. Hypertens Res 2009; 32: 289-298.

16 Emdin M, Pompella A, Paolicchi A. Gamma-glutamyltransferase, atherosclerosis, and cardiovascular disease: triggering oxidative stress within the plaque. Circulation 2005; 112: 2078-2080.

17 Pompella A, Emdin M, Passino C, Paolicchi A. The significance of serum gamma-glutamyltransferase in cardiovascular diseases. Clin Chem Lab Med 2004; 42: 1085-1091.

18 Ruttmann E, Brant LJ, Concin H, Diem G, Rapp K, Ulmer H. Gamma-glutamyltransferase as a risk factor for cardiovascular disease mortality: an epidemiological investigation in a cohort of 163944 Austrian adults. Circulation 2005; 112: 2130-2137.

19 Brenner H, Rothenbacher D, Arndt V, Schuberth S, Fraisse E, Fliedner TM. Distribution, determinants, and prognostic value of gamma-glutamyltranspeptidase for all-cause mortality in a cohort of construction workers from south Germany. Prev Med 1997; 26: 305-310.

20 Karlson BW, Wiklund O, Hallgren P, Sjolin M, Lindqvist J, Herlitz J. Ten-year mortality amongst patients with a very small or unconfirmed acute myocardial infarction in relation to clinical history, metabolic screening and signs of myocardial ischaemia. J Intern Med 2000; 247: 449-456.

21 Yusuf S, Hawken S, Ounpuu S, Bautista L, Franzosi MG, Commerford P, Lang CC, Rumboldt Z, Onen CL, Lisheng L, Tanomsup S, Wangai Jr P, Razak F, Sharma AM, Anand SS, INTERHEART Study Investigators. Obesity and the risk of myocardial infarction in 27,000 participants from 52 countries: a case-control study. Lancet 2005; 366: 1640-1649. 